\section{Gastric Perforation Due to Ventriculoperitoneal Shunt}

Unusual complications can result from the use of familiar devices. The following case highlights one such instance.

A 33-year-old nurse was admitted to our hospital with a 1-month history of abdominal pain, vomiting and headache. Previously she had had a ventriculoperitoneal shunt of unspecified type inserted for congenital hydrocephalus.

Clinical examination on admission showed her to be afebrile with a soft and nontender abdomen. Bowel sounds were normal. Neurological examination revealed no specific abnormality and fundoscopy was normal.

Laboratory investigation showed haematological and biochemical measurements to all be unremarkable. Plain abdominal radiography identified the ventriculoperitoneal shunt in the left hypochondrium but abdominal ultrasound and computed tomography scan revealed no abnormality.

Oesophagogastroduodenoscopy revealed the cause of the abdominal pain. The peritoneal catheter had perforated the anterior wall of the stomach and was seen lying over the greater curve where a small pool of cerebrospinal fluid was identified (Figure 1). The shunt was repositioned laparoscopically, and the patient's symptoms settled.

A review of the literature revealed two previous cases of gastric perforation by peritoneal shunt $[1,2]$. This is therefore an unusual situation but should be considered in any patient known to have a ventriculoperitoneal shunt who develops recurrent attacks of abdominal pain.

\section{Acknowledgements}

We wish to thank the two surgeons involved in this case, Mr G. A. Ponting and Mr J. A. Kellerman, and to thank Marilyn Lucas for typing the manuscript.

\section{A. L. Hart, D. Hollanders}

Havering Hospitals NHS Trust, Romford, UK

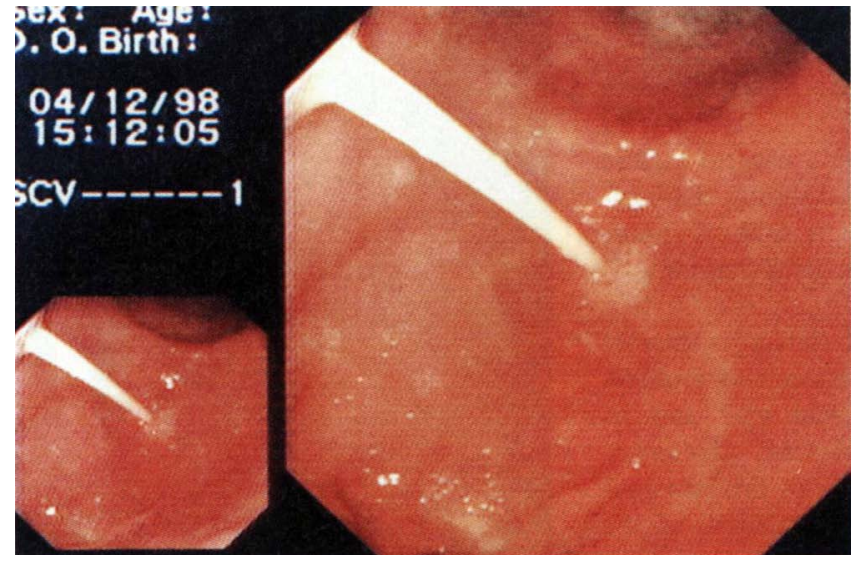

Figure 1 An endoscopic image showing the distal end of a ventriculoperitoneal shunt perforating the anterior wall of the stomach and discharging a small pool of cerebrospinal fluid onto the greater curve

\section{References}

${ }^{1}$ Alsonso-Vanegas M, Alvarez JL, Delgado L, et al. Gastric perforation due to a ventriculoperitoneal shunt. Pediatr Neurosurg 1994; 21 (3): 192-194

${ }^{2}$ Nishijima M, Endoh S, Ohyama H, Higuchi H. Gastric perforation by a ventriculoperitoneal shunt. Neurosurgery 1982; 10: $574-576$
Corresponding Author

D. Hollanders, F.R.C.P.

Dept. of Gastroenterology

Havering Hospitals NHS Trust

Waterloo Road

Romford

Essex RM7 0BE

United Kingdom

Fax: $\quad+44-1708-708125$ 